\title{
The use of high-sensitivity sapphire cells in high pressure NMR spectroscopy and its application to proteins
}

\author{
W. Kremer*, M.R. Arnold, N. Kachel and H.R. Kalbitzer \\ Institut für Biophysik und Physikalische Biochemie, Universität Regensburg, P.O. Box, \\ 93040 Regensburg, Germany
}

\begin{abstract}
The application of high pressure in bioscience and biotechnology has become an intriguing field in un/refolding and misfolding processes of proteins. NMR spectroscopy is the only generally applicable method to monitor pressure-induced structural changes at the atomic level in solution. Up to now the application of most of the multidimensional NMR experiments is impossible due to the restricted volume of the high pressure glass cells which causes a poor signal-to-noise ratio. Here we present high strength single crystal sapphire cells which double the signal-to-noise ratio. This increased signal-to-noise ratio is necessary to perform, for example, phophorus NMR spectroscopy under variable pressures.

To understand the effect of pressure on proteins, we need to know the pressure dependence of ${ }^{1} \mathrm{H}$ chemical shifts in random coil model tetrapeptides. The results allow distinguishing structural changes from the pressure dependence of the chemical shifts. In addition, the influence of pressure on the buffer system was investigated.

Since high pressure was shown to populate intermediate amyloidogenic states of proteins the investigation of pressure effects on proteins involved in protein conformational disorders like Alzheimer's Disease (AD) and Transmissible Spongiform Encephalopathies (TSE) is of keen interest. ${ }^{1} \mathrm{H}-{ }^{15} \mathrm{~N}-\mathrm{TROSY}$-spectra were acquired to study the effects of pressure and temperature on chemical shifts and signal volumes of the human prion protein. These measurements show identical pressure sensitivity of $h u \operatorname{PrP}(23-230)$ and $h u \operatorname{PrP}(121-230)$. First results suggest a folding intermediate for the human prion protein which can be populated by high hydrostatic pressure.
\end{abstract}

\section{Introduction}

High pressure NMR-spectroscopy can yield local information about mechanical and dynamical properties of proteins and can be used to stabilise folding and unfolding intermediates [1-3]. At pressures of $200 \mathrm{MPa}$ the phase behaviour of water allows the observation of protein denaturation in aqueous solution at temperatures down to $255 \mathrm{~K}$ [4]. In addition, high pressure influences protein aggregation and association as well [5].

Currently, two conceptually different methods are applied in high pressure NMR experiments. The first method is known as the high pressure probe method and uses specifically designed non-magnetic metal autoclaves [6,7]. The second method has been called 'Yamada glass cell method' [8-10]. Generally pressurising the whole probe would allow obtaining very high pressures. Nevertheless, the design of special metallic high pressure probes leads to severe problems: (i) limitation of space in high resolution high field NMR spectrometers, (ii) perturbations of the magnetic field homogeneity and (iii) the difficulty

\footnotetext{
*Corresponding author. Tel.: +49 941 9432185; Fax: +49 941 9432479; E-mail: werner.kremer@ biologie.uni-regensburg.de.
} 
to construct reliable low impedance radiofrequency feedthroughs through the thick metal parts of the autoclaves. The big advantage of the 'Yamada glass cell method' is its use in all commercially available probe heads. A modified version by Lang and Lüdemann [11] is used in our laboratory. Due to a rather small sample volume in the thick-walled sample tubes the glass cell method displays an inherent low sensitivity. Typically, borosilicate or quartz glass capillaries with an outer diameter of $5 \mathrm{~mm}$ and an inner diameter of 1.0 to $1.2 \mathrm{~mm}$ are required to withstand pressures up to $200 \mathrm{MPa}[12,13]$.

\section{Sapphire cells lead to higher sensitivity}

In search for a better signal-to-noise ratio we devised a sapphire cell system (Fig. 1) with single crystalline sapphire capillaries having an inner diameter of $1.78 \mathrm{~mm}$ and an outer diameter of $3.14 \mathrm{~mm}$, which are available from Saphikon (Milford, New Hampshire 03055, USA). ${ }^{1} \mathrm{H}-{ }^{15} \mathrm{~N}-\mathrm{HSQC}$ spectra were measured on a uniformly ${ }^{15} \mathrm{~N}$-enriched $0.5 \mathrm{mM}$ sample of the cold shock protein (Csp) from Thermotoga maritima in a sapphire cell and under identical experimental conditions in a borosilicate glass cell with $5 \mathrm{~mm}$ outer diameter and $1.2 \mathrm{~mm}$ inner diameter [14]. A comparison of selected regions of the measured ${ }^{1} \mathrm{H}-{ }^{15} \mathrm{~N}-\mathrm{HSQC}$ spectra with the data plotted at the same contour level is shown in Fig. 2. The use of sapphire cells leads to much better signal-to-noise ratio as is expected from the approximately two-times larger active volume in the probe. 1D slices through the maximum of the $\mathrm{H}^{\mathrm{N}}$ crosspeaks of $\mathrm{K} 19$ in the 2D HSQC spectra show an increase of the signal-to-noise ratio by a factor of 2 [14].

\section{Pressure shifts proline cis-trans-isomerization}

A first result of the sapphire cells shows the pressure sensitivity of the cis-trans-isomerization of the proline peptide bond. In the NMR spectra, both isomers can be distinguished by the different chemical shift values of the prolyl signals. For our experiments we used a $5 \mathrm{mM}$ solution of the random-coil peptide GGPA (glycyl-glycyl-prolyl-alanine). In a recent study we could not find a significant pressure dependence of the cis-trans-equilibrium using a glass cell [15] within the experimental error. The conformational equilibrium of the prolyl peptide bond was studied by integrating the $\mathrm{H}^{\alpha}$-signals of cis- and trans-isomer of proline which are well separated in the 1D-spectra (Fig. 3). Integration of the resonance lines gives the population of the corresponding isomer. As a result now a significant shift of the equilibrium constant $K=[$ trans $] /[$ cis $]$ can be observed when the pressure is varied. Increasing pressure leads to a higher population of the $c i$ s-isomer of the peptide bond. At $0.1 \mathrm{MPa}$ and $305 \mathrm{~K}$ the value of $K$ is $3.381 \pm 0.008$. Assuming a logarithmic pressure dependence the change of the equilibrium constant $\mathrm{d} \ln K / \mathrm{d} p$ with pressure can be calculated as $-10^{-4} \mathrm{MPa}^{-1}$ with a correlation coefficient of 0.94 . The difference of the partial molar volume $\Delta V_{0}$ is $-0.25 \mathrm{ml} \mathrm{mol}^{-1}$ at $305 \mathrm{~K}$ [14]. A possible explanation for this effect is the break of two H-bonds which are forming $\gamma$-turns [16] in the short peptide GGPA between the carboxyl $\mathrm{C}$ and the amide $\mathrm{N}$ of the $\mathrm{C}$-terminal alanine and the second glycine but may also represent differences of the partial charges of the peptide bond itself in the two isomers.

\section{High pressure effects in model peptides}

In high resolution solution NMR spectroscopy a wealth of information about the chemical shift in model random coil peptides is available [17]. For high pressure NMR spectroscopy we evaluated the 

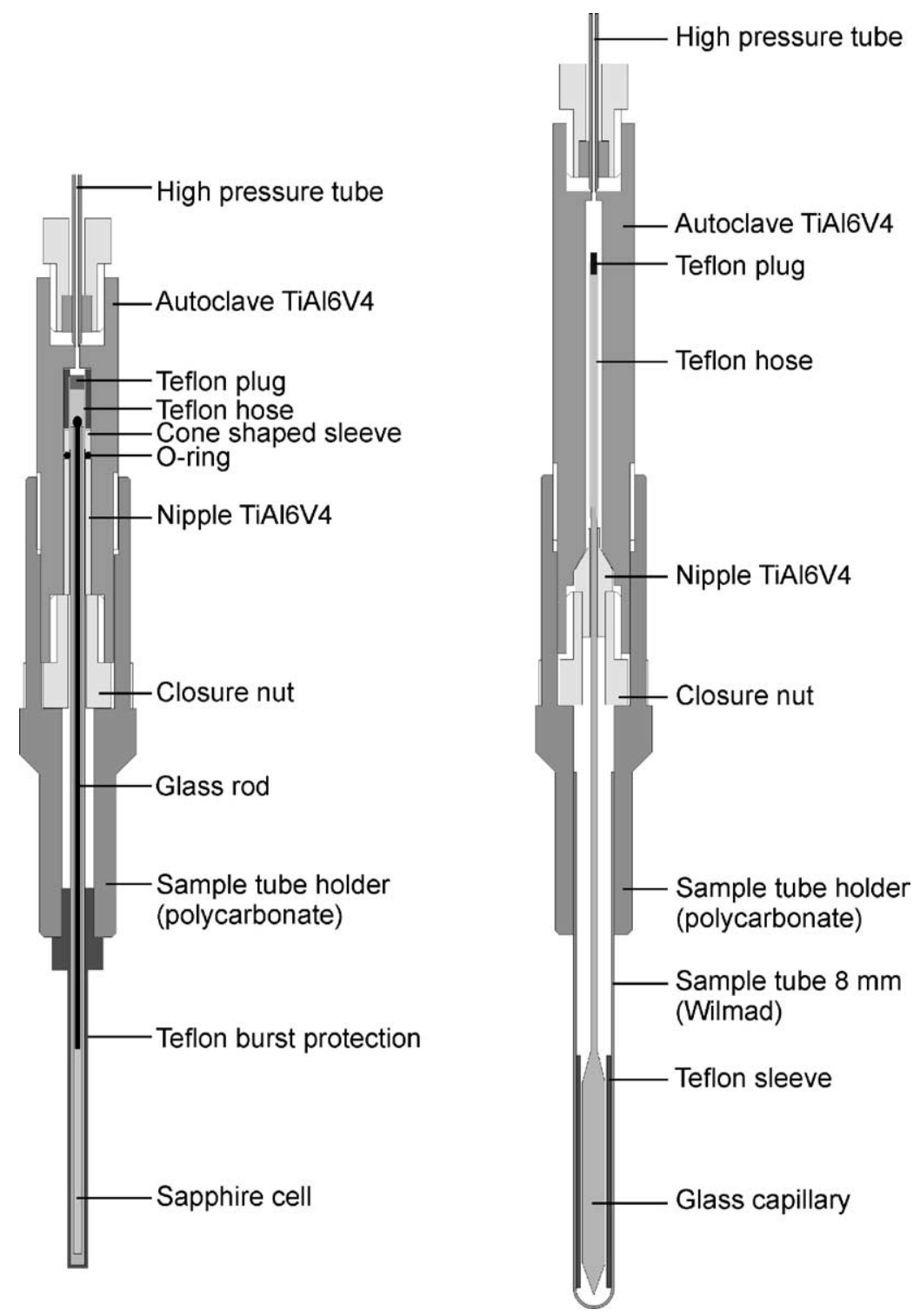

Fig. 1. Left: Sapphire cell system with O-ring gasket. The pressurising fluid and sample are separated by a Teflon shrink hose, which is closed by an Teflon plug. Outer diameter of the sapphire cell $3.18 \mathrm{~mm}$, inner diameter $1.73 \mathrm{~mm}$. As burst protection either a Teflon hose with $0.2 \mathrm{~mm}$ wall thickness or an especially manufactured closed Teflon tube (PTFE, outer diameter $4.8 \mathrm{~mm}$, inner diameter $3.5 \mathrm{~mm}$ ) was used. Right: Glass cell system with cone shaped metal sealing. The Duran 50 borosilicate glass capillary is glued into a cone shaped TiAl6V4 nipple. Outer diameter of the glass capillary $5.0 \mathrm{~mm}$, inner diameter $1.2 \mathrm{~mm}$.

influence of pressure on the chemical shift of all of these model peptides [15]. The pressure dependence of the ${ }^{1} \mathrm{H}-\mathrm{NMR}$ chemical shift of the amino acids $\mathrm{X}$ in the random-coil model peptides Gly-Gly-X-Ala was studied for the 20 common amino acids at two $\mathrm{pH}$ values (pH 5.0 and 5.4 in phosphate buffer) at $305 \mathrm{~K}$ in the pressure range from 0.1 to $200 \mathrm{MPa}$ and showed only two nonlinear behaving examples: the backbone amide proton resonance of glutamate and the side chain NH-resonance $\mathrm{H}^{\varepsilon 1}$ of tryptophan [15]. The methylation of the C-terminal carboxyl group which has a $\mathrm{pK}_{\mathrm{a}}$-value of approximately 3.3 led to a 

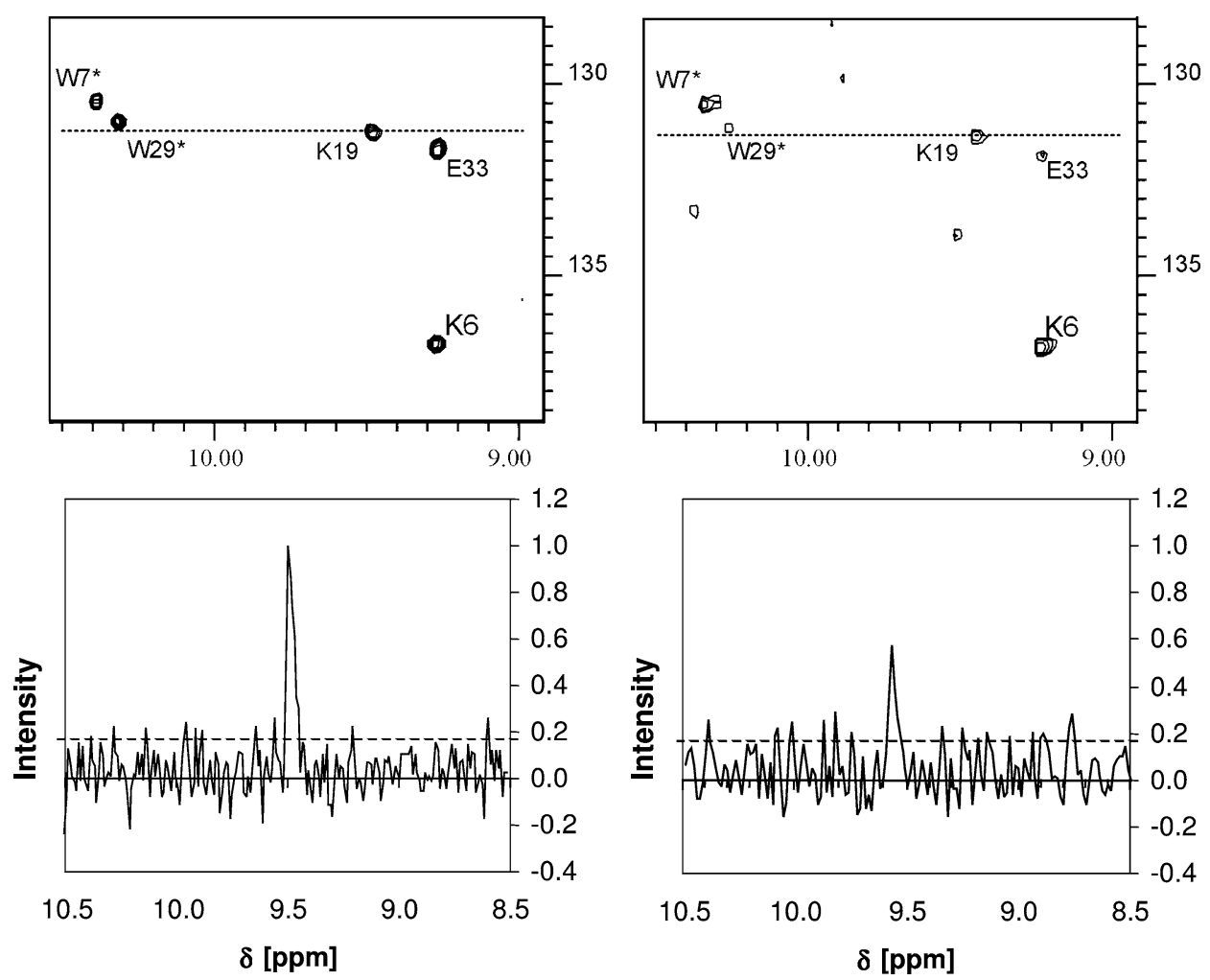

Fig. 2. Top: Selected regions of ${ }^{1} \mathrm{H}_{-}{ }^{15} \mathrm{~N}$ correlation spectra. The sample contained $0.5 \mathrm{mM}$ uniformly ${ }^{15} \mathrm{~N}$-enriched cold shock protein from Thermotoga maritima (TmCsp) in $50 \mathrm{mM}$ phosphate buffer ( $\mathrm{pH}$ 6.5), $20 \mathrm{mM} \mathrm{NaCl}, 0.2 \mathrm{mM} \mathrm{Na}$-EDTA, $0.1 \mu \mathrm{M}$ $\mathrm{NaN}_{3}, 10 \% \mathrm{D}_{2} \mathrm{O}$ and $90 \%{ }^{1} \mathrm{H}_{2} \mathrm{O}$. Gradient selected sensitivity enhanced ${ }^{1} \mathrm{H}_{-}{ }^{15} \mathrm{~N}-\mathrm{HSQC}$ spectra were recorded under identical experimental conditions either in a sapphire cell (left) with an outer diameter $3.2 \mathrm{~mm}$, inner diameter $1.7 \mathrm{~mm}$ or a borosilicate glass capillary (right) with an outer diameter of $5.0 \mathrm{~mm}$ and an inner diameter of $1.2 \mathrm{~mm}$. Data were recorded with a $8 \mathrm{~mm}$ inverse triple resonance probe head at $600 \mathrm{MHz}$ proton frequency. Total acquisition time approximately $2.5 \mathrm{~h}$, resolution 2048 points in the direct dimension and 256 points in the indirect dimension. The temperature was adjusted to $303 \mathrm{~K}$. The same contour levels for the two experiments were used. Bottom: 1D-slices through the maximum of the $\mathrm{H}^{\mathrm{N}}$-signal of K19. (Reprinted with permission.)

disappearance of the nonlinear pressure dependence indicating an interaction between the $\mathrm{Glu}{ }^{1} \mathrm{H}^{\mathrm{N}}$ and the C-terminal Ala in the non-methylated form (see Table 1).

\section{High pressure NMR on the human prion protein}

We investigated the effects of pressure and temperature on chemical shifts and signal volumes of two variants of the human prion protein, $h u \operatorname{PrP}(121-230)$ and $h u \operatorname{PrP}(23-230) .1 \mathrm{D}{ }^{1} \mathrm{H}-\mathrm{NMR}$ as well as ${ }^{1} \mathrm{H}-$ ${ }^{15} \mathrm{~N}$-TROSY spectra of $h u \operatorname{PrP}^{\mathrm{c}}(121-230)$ and $h u \operatorname{PrP}^{\mathrm{c}}(23-230)$ at variable pressure and temperature show that the application of pressure is reversible and we see virtually no difference between $h u \operatorname{PrP}^{\mathrm{c}}(121-230)$ and $h u \operatorname{PrP}^{\mathrm{c}}(23-230)$ [18].

We observed $1 \mathrm{D}{ }^{1} \mathrm{H}-$ and $2 \mathrm{D}{ }^{1} \mathrm{H}_{-}{ }^{15} \mathrm{~N}$-TROSY NMR spectra of ${ }^{15} \mathrm{~N}$ enriched $h u \operatorname{PrP}(23-230)$ and $h u \operatorname{PrP}(121-230)$ at $\mathrm{pH} 4.5$ (acetate buffer) at variant pressures and temperatures. At $20^{\circ} \mathrm{C}$ we applied hydrostatic pressures of $0.1,50,100,125,150,175$ and $200 \mathrm{MPa}$ at both, $h u \operatorname{PrP}(23-230)$ and $h u \operatorname{PrP}(121-$ 230). At ambient pressure and $200 \mathrm{MPa}$ we studied the temperature dependence of $h u \operatorname{PrP}(23-230)$ and 

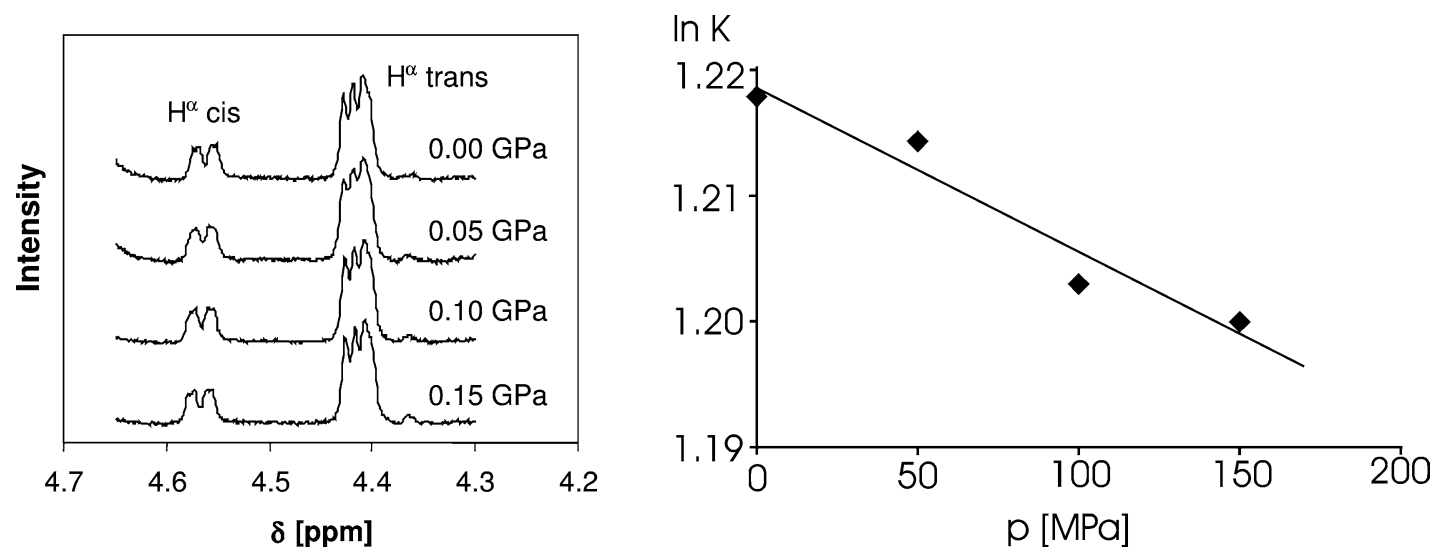

Fig. 3. Left: Part of $1 \mathrm{D}{ }^{1} \mathrm{H}-\mathrm{NMR}$ spectra at various pressures showing the $\mathrm{H}^{\alpha}$-signal of proline in cis- and trans-conformation, respectively. The sample contained $5 \mathrm{mM}$ GGPA in $50 \mathrm{mM}$ Tris/ $\mathrm{HCl}$ buffer $(\mathrm{pH} 7.0)$ and $0.1 \mathrm{mM}$ DSS in $99 \% \mathrm{D}_{2} \mathrm{O}$. The pressure was changed from $0.1 \mathrm{MPa}$ to $150 \mathrm{MPa}$ in steps of $50 \mathrm{MPa}$ at a temperature of $305 \mathrm{~K}$. Right: The ratio of the integrals of the signals of the trans- to the cis-conformer are plotted as function of pressure. (Reprinted with permission.)

Table 1

Chemical shifts and pressure coefficients of the amide protons of amino acid Glu in Gly-Gly-X-Ala and ${ }^{\mathrm{b}}$ Gly-Gly-X-Ala-methyl at $305 \mathrm{~K}$ in aqueous solution at $\mathrm{pH} 5.4^{\mathrm{a}}$

\begin{tabular}{|c|c|c|c|c|c|c|}
\hline \multirow[t]{2}{*}{$\overline{\mathrm{X} 3}$} & \multicolumn{3}{|c|}{ First order model } & \multicolumn{3}{|c|}{ Second order model } \\
\hline & $\begin{array}{c}\delta_{0}^{\mathrm{HN}} \\
{[\mathrm{ppm}]}\end{array}$ & & & $\begin{array}{c}\delta_{0}^{\mathrm{HN}} \\
{[\mathrm{ppm}]}\end{array}$ & $\begin{array}{c}\delta_{\Delta 2 p}^{\prime \mathrm{HN}} \\
{\left[\mathrm{ppm} \mathrm{GPa}^{-1}\right]}\end{array}$ & $\begin{array}{c}\delta_{\Delta 2 p}^{\mathrm{HN}} \\
{\left[\mathrm{ppm} \mathrm{GPa}^{-2}\right]}\end{array}$ \\
\hline$\overline{\text { Glu }}$ & 8.522 & -0.026 & \pm 0.004 & 8.525 & -0.15 & 0.63 \\
\hline Glu $^{\mathrm{b}}$ & 8.709 & 0.017 & \pm 0.001 & 8.709 & -0.98 & 0.53 \\
\hline
\end{tabular}

${ }^{\mathrm{a}}$ The chemical shift $\delta_{0}^{\mathrm{HN}}$ at $0.1 \mathrm{MPa}$, the linear pressure coefficient $\delta_{\Delta p}^{\mathrm{HN}}$, the first order and second order pressure coefficients $\delta^{\prime}{ }_{\Delta 2 p}^{\mathrm{HN}}, \delta_{\Delta 2 p}^{\mathrm{HN}}$ were obtained by fitting the data according to [15].

found that at $60^{\circ} \mathrm{C}$ the $1 \mathrm{D}{ }^{1} \mathrm{H}-\mathrm{NMR}$ spectra were characteristic of an unfolded protein. Here, the release of the pressure did not result in a refolded protein. Up to $50^{\circ} \mathrm{C}$ the pressure-induced unfolding was completely reversible. Figure 4 shows $2 \mathrm{D}^{1} \mathrm{H}^{-15} \mathrm{~N}$-TROSY spectra of $h u \operatorname{PrP}(121-230)$ and $h u \operatorname{PrP}(23-230)$ at ambient pressure and $200 \mathrm{MPa}$. Increasing the pressure results in changes in the resonance frequency. In addition even in the TROSY spectra the increased pressure leads to more broadened signals, indicating a tentative increase in molecular mass or exchange (broadening) between the native and a pressurestabilized conformer. Many signals broaden such that they disappear from the spectra. Between 175 and $200 \mathrm{MPa}$ the amide protons of residues 128, 131, 134, 136, 139, 141-144, 150, 156, 160, 161, 163, 174, $178,182,199,200,202,210,214,215,217$ and 221 are not observable in case of $h u \operatorname{PrP}(121-230)$. Especially, residue 131 disappears already at $125 \mathrm{MPa}$, while residues 139, 141, 160, 161, 163 and 178 are undetectable at $150 \mathrm{MPa}$. These residues mainly cluster to the loop between the strand $\beta 1$ and helix $\alpha 1$, near helix $\alpha 3$ and close to the $\beta$-sheet (see Fig. 5). In case of $h u \operatorname{PrP}(23-230)$ due to severe signal overlap induced by the pressure-induced line broadening only the disappearance of residues 131, 139, 141, 156, 157 and 178 can be reliably confirmed. By releasing the pressure we observe the original spectra at ambient pressure again, thus the pressure-induced changes are completely reversible. Upfield shifted methyl groups of Ile139, Leu130 and Ile182 show a similar broadening (data not shown) indi- 

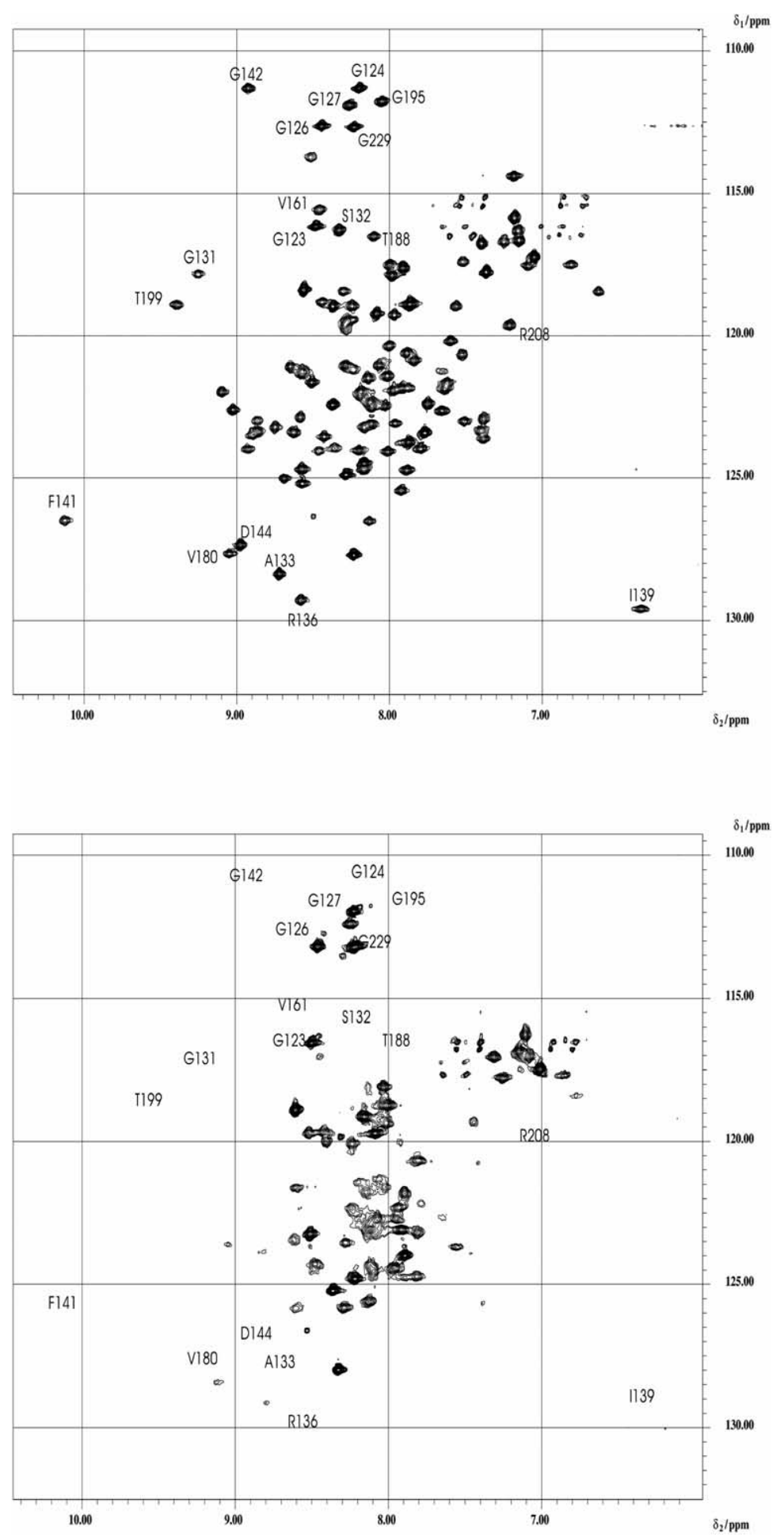

Fig. 4. $2 \mathrm{D}{ }^{1} \mathrm{H}_{-}{ }^{15} \mathrm{~N}$-TROSY spectra of $h u \operatorname{PrP}(121-230)$ at ambient pressure (top) and $200 \mathrm{MPa}$ (bottom). 


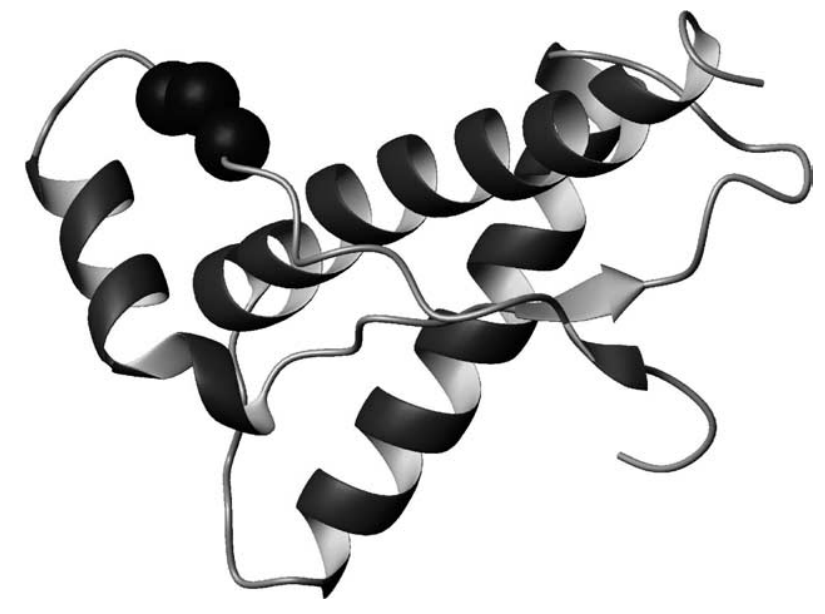

Fig. 5. Most pressure-sensitive region mapped on the tertiary structure of $h u \operatorname{PrP}$ (PDB-ID: 1QM2).

cating primarily an underlying structural conformational change rather than chemical exchange of the amide protons as origin for the line broadening [18].

\section{Summary}

In summary, we can state that the combination of high hydrostatic pressure and solution NMR spectroscopy allows studying local dynamics of proteins which might be important for function apart from the dynamic information gained from relaxation measurements. The examples described above are important for regulatory processes such as signal transduction. The aggregation of proteins into fibrils as seen in many of the protein conformational disorders might involve specific interaction sites of target proteins which can be characterized under steady state conditions in high pressure high field NMR spectroscopy. Especially the reversibility of these interaction modes and thus their population can be fine tuned by optimising the three parameters $\mathrm{pH}$, temperature and pressure.

\section{Acknowledgements}

We thank Kurt Wüthrich and Ralph Zahn for supplying us with a ${ }^{15} \mathrm{~N}$-enriched sample of $h u \operatorname{PrP}^{\mathrm{c}}(121-$ 230) and $h u \operatorname{PrP}^{\mathrm{c}}(23-230)$. We thank the Deutsche Forschungsgemeinschaft for financial support.

\section{References}

[1] J.L. Silva, D. Foguel and C. Royer, Pressure provides new insights into protein folding, dynamics and structure, Trends in Biochem. Sci. 26 (2001), 612-618.

[2] K. Akasaka, H. Li, H. Yamada, R. Li, T. Thoresen and C.K. Woodward, Pressure response of protein backbone structure. Pressure-induced amide ${ }^{15} \mathrm{~N}$ chemical shifts in BPTI, Prot. Sci. 8 (1999), 1946-1953.

[3] K. Akasaka and H. Yamada, On-line cell high-pressure nuclear magnetic resonance technique: application to protein studies, Methods in Enzymology 338 (2001), 134-158.

[4] J. Jonas, Nuclear magnetic resonance at high pressure, Science 216 (1982), 1179-1184.

[5] M. Gross and R. Jaenicke, Proteins under pressure. The influence of high hydrostatic pressure on structure, function and assembly of proteins and protein complexes, European Journal of Biochemistry / FEBS 221(2) (1994), 617-630. 
[6] F. Bachl, NMR-Spektroskopische Untersuchungen zur Dynamik einfacher Kohlen-wasserstoffe bis 600 MPa, Dissertation, Universität Regensburg, 1988.

[7] L. Ballard, A. Yu, C. Reiner and J. Jonas, A high pressure, high-resolution NMR probe for experiments at $500 \mathrm{MHz}$, J. Mag. Res. 133 (1998), 190-193.

[8] H. Yamada, Pressure-resisting glass cell for high pressure, high-resolution NMR measurements, Rev. Sci. Instr. 45 (1974), 540-542.

[9] W.E. Price and H.-D. Lüdemann, NMR and diaphragm cell techniques for the study of molecular dynamics in fluids, in: High Pressure Techniques in Chemistry and Physics: A Practical Approach, W.B. Holzapfel and N.S. Isaacs, eds, Oxford University Press, Oxford 1997, Chapter 5, p. 225.

[10] H. Yamada, K. Nishikawa, M. Honda, T. Shimura, K. Akasaka and K. Tabayashi, Pressure-resisting cell for high-pressure, high-resolution nuclear magnteic resonance measurement at very high magnetic fields, Rev. Sci. Instr. 72 (2001), 14631471.

[11] Lang and Lüdemann, in: NMR Basic Principles and Progress, P. Diehl, E. Fluck, H. Günther, R. Kosfeld and J. Seelig, eds, Vol. 24, 1990, pp. 129-187.

[12] F.X. Prielmeier, E.W. Lang, R.J. Speedy and H.-D. Lüdemann, The pressure dependence of self diffusion in supercooled light and heavy water, Ber. Bunsen-Ges. Phys. Chem. 92 (1988), 1111.

[13] M.R. Arnold and H.-D. Lüdemann, The pressure dependence of self-diffusion and spin lattice relaxation in cold and supercooled $\mathrm{H}_{2} \mathrm{O}$ and $\mathrm{D}_{2} \mathrm{O}$, Phys. Chem. Chem. Phys. 4 (2002), 1581-1586.

[14] M.R. Arnold, H.R. Kalbitzer and W. Kremer, High-sensitivity sapphire cells for high pressure NMR spectroscopy on proteins, J. Magn. Resonance 161 (2003), 127-131.

[15] M.R. Arnold, W. Kremer, H.-D. Lüdemann and H.R. Kalbitzer, ${ }^{1}$ H-NMR parameters of common amino acid residues measured in aqueous solutions of the linear tetrapeptides Gly-Gly-X-Ala at pressures between 0.1 and $200 \mathrm{MPa}$, Biophys. Chem. 96 (2002), 129-140.

[16] G. Némethy and M.P. Printz, The $\gamma$-turn, a possible folded conformation of the polypeptide chain. Comparison with the $\beta$-turn, Macromolecules 5 (1972), 755-758.

[17] D.S. Wishart, C.G. Bigam, H. Arne, R.S. Hodges and B.D. Sykes, 1H, 13C, 15N random coil NMR shifts of the common amino acids. I. Investigation of nearest neighbour effects, J. Biomol. NMR 5 (1995), 67-81.

[18] W. Kremer, N. Kachel and H.R. Kalbitzer, A glimpse of an intermediate state and implications for the species barrier of the human prion protein. In preparation. 


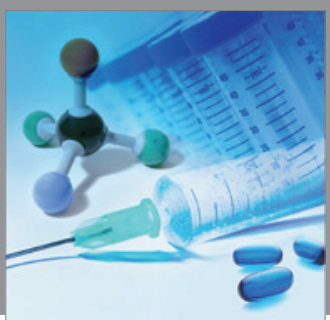

International Journal of

Medicinal Chemistry

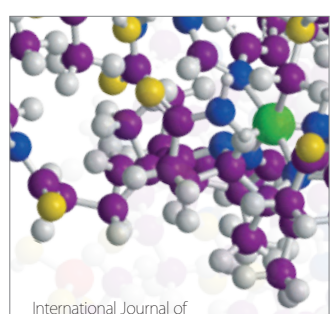

Carbohydrate Chemistry

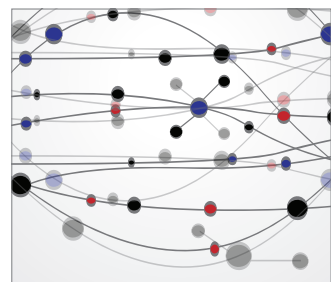

The Scientific World Journal
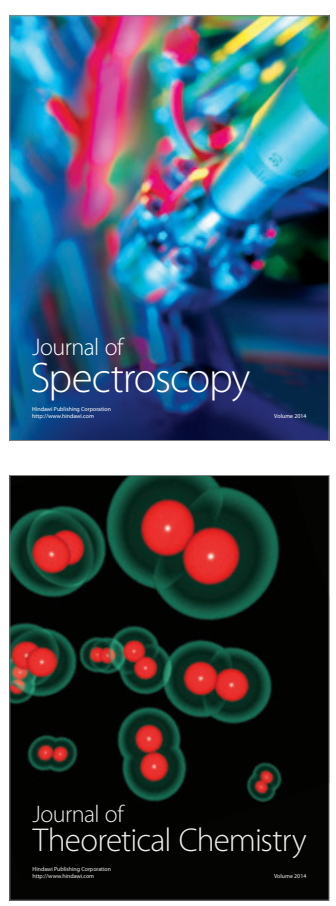
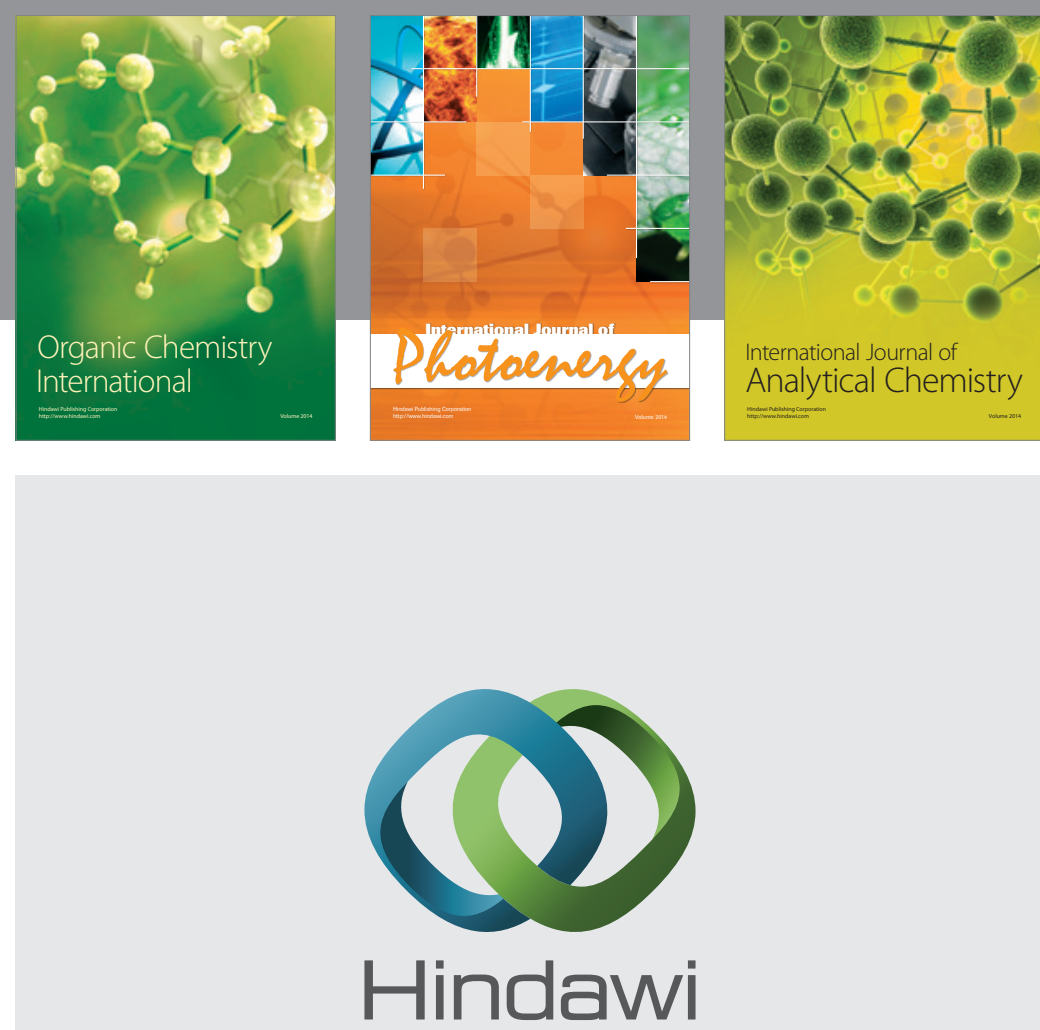

Submit your manuscripts at

http://www.hindawi.com
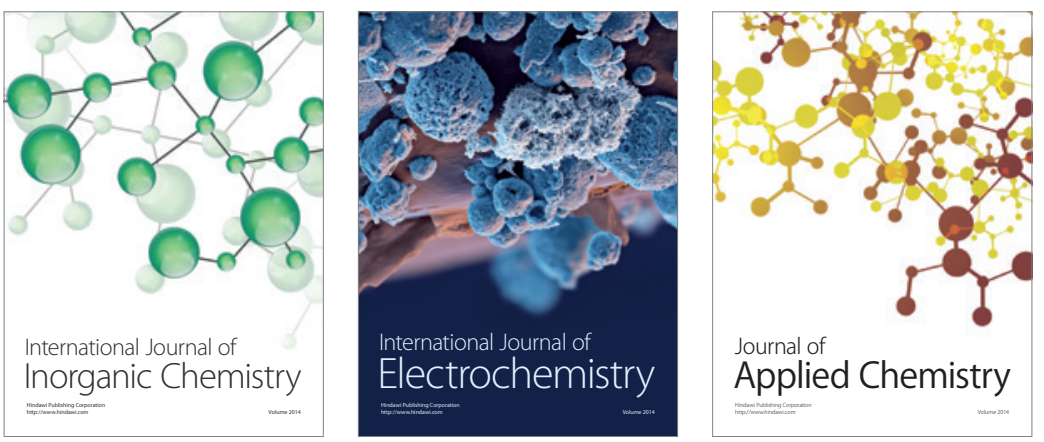

Journal of

Applied Chemistry
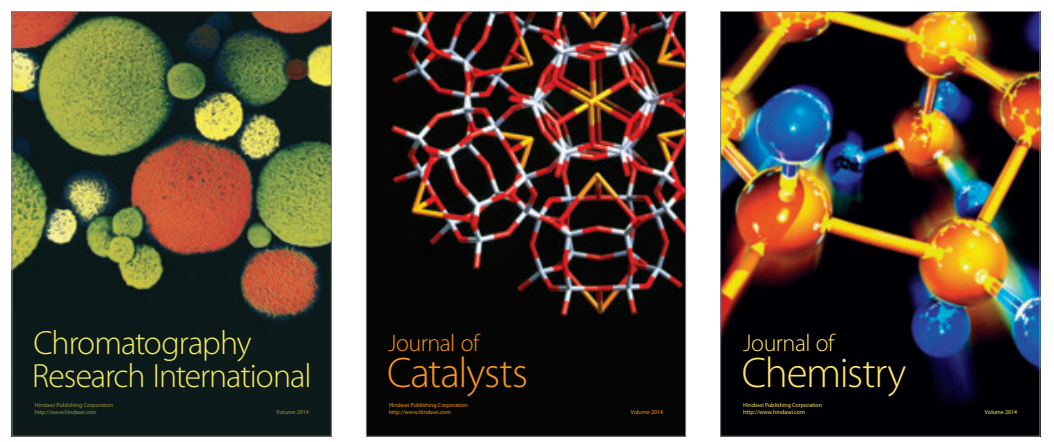
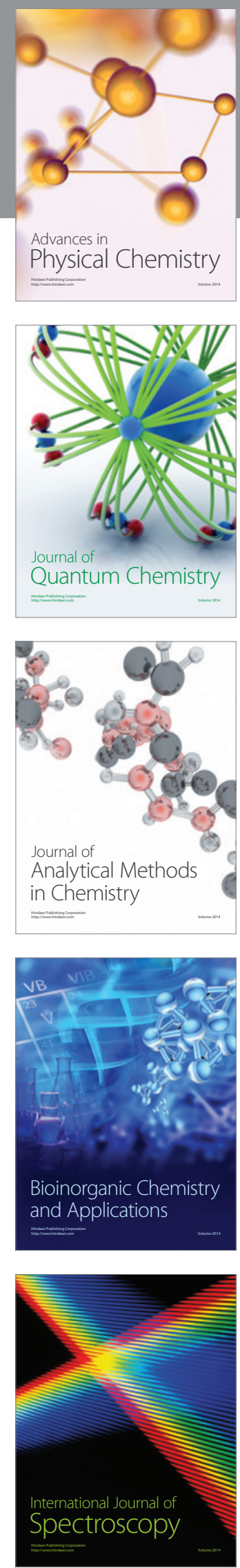